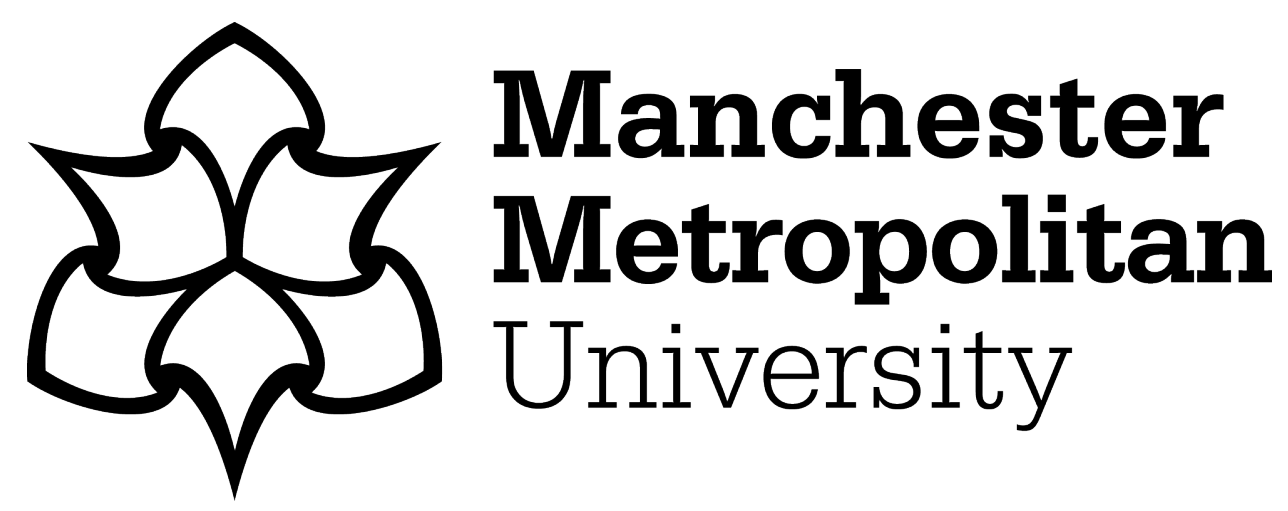

Walshaw, M and Brown, T (2012) Affective productions of mathematical experience. Educational Studies in Mathematics, 80 (1-2). pp. 185-199. ISSN 0013-1954

Downloaded from: https://e-space.mmu.ac.uk/237936/

Version: Accepted Version

Publisher: Springer (part of Springer Nature)

DOI: https://doi.org/10.1007/s10649-011-9370-x

Please cite the published version 


\title{
AFFECTIVE PRODUCTIONS OF MATHEMATICAL EXPERIENCE
}

\author{
Margaret Walshaw and Tony Brown
}

ABSTRACT: In underscoring the affective elements of mathematics experience, we work with contemporary readings of the work of Spinoza on the politics of affect, to understand what is included in the cognitive repertoire of the Subject. We draw on those resources to tell a pedagogical tale about cognition and affect in settings of mathematical learning. Our interest is first captured in the way in which one teacher's priority of establishing an inclusive learning community, occasionally harboured what appeared to be pedagogically restrictive conceptions of mathematics. Yet, the classroom practices that produced these conceptions promoted the students' motivation and provided meaningful access to mathematical learning within the classroom collectivity. In a second example, the postponement of scientific encapsulation in bodily imitations of planetary movement, kept alive a shared dynamic sense of an elliptical orbit. In both of these cases we draw on Spinoza's work to show how the affectivity of classroom practice constituted conceptions of cognition and of mathematical activity crucially linked to the imperatives of participation.

\section{INTRODUCTION}

Doug McLeod (1992), in a seminal publication, sparked considerable interest in the relationship between affect and cognition, when he proposed that the affective domain encompassed "a wide range of beliefs, feelings and moods that are generally regarded as going beyond the domain of cognition" (p. 576). Researchers soon began to explore mathematics education through the code words of anguish, anxiety, attitudes, autonomy, beliefs, confidence, curiosity, disaffection, dislike, emotions, enthusiasm, fear, feelings, frustration, hostility, interest, intuition, moods, panic, perseverance, sadness, satisfaction, self-concept, self-efficacy, suffering, tension, viewpoint and worry (see e.g., Hannula, 2002; Ma, 1999; Martinez \& Martinez, 2003). From those investigations important conclusions have been drawn with respect to the affect/cognition relation. It is possible to name these affective entities as causes, in just the same way as it is possible to name cognition as the effect.

But mathematics education need not necessarily draw cognition and affect together by means of causal links alone. Indeed, we are currently witnessing a plethora of connections, drawn from theories of discursive practice (e.g., Evans, 2000; Walshaw, 2010), of embodiment (Drodge \& Reid, 2000), of somatic markers (e.g., Brown \& Reid, 2004), of neuroscience (Schlöglmann, 2002), of representation (e.g., Goldin, 2000), of psychoanalysis (e.g., Bibby, 2010; Brown, 2008), and of situated practice (e.g., Lave, 1988). All these groundings share the realisation that classrooms also team with other kinds of activities that in some way impact on cognition. Teachers stand at the front of the room, write on the board, show powerpoint slides, assign mathematical tasks, offer explanations, listen and notice, facilitate discussions, set homework, evaluate students' book work and check attendance. Students sit at desks, work individually and in groups, watch and listen to the teacher, work from textbooks and worksheets, engage or otherwise in problem solving, and check the clock. In all these activities, the content and contours of what happens constantly change. The question of cognition becomes a question of how teachers and students handle the activities; how they act upon them and transform them. 
That question is central to the following discussion in which we make our own links between cognition and affect. In foregrounding affect through an exploration of some instances of learning, we first look at the arguments about cognition that have crystallised in our cognate traditions in order to demonstrate that, despite the broad links with our project in exploring thinking and being, conventional accounts typically get ahold of their materials in remarkably different and indeed almost incommensurable ways from ours. We impose our own empirical discipline on cognition and specifically on the part that affect plays in pedagogical realities. In that task we are indebted to contemporary readings (e.g., Badiou, 2009; Deleuze, 1990, 1997; Duffy, 2006; Ruddick, 2010; Williams, 2007), of the work of the $17^{\text {th }}$ century Dutch philosopher Baruch (or Benedictus) Spinoza on the politics of affect, for marking a less familiar sensibility towards cognition. Spinoza provides us with the resources for theorising the unrepresentable that, in turn, allow us to understand what is included in the cognitive repertoire of the Subject.

\section{EXPLAINING COGNITION}

There are many ways, of course, to punctuate cognition. For example, both first wave and second wave theories, as classified by de Corte, Greer, and Verschaffel (1996), promote cognition through the social/individual relation. Between the two, however, there are differences in the way in which the relation is expressed. There are also differences in the particular kind of subject that is deemed necessary to the formulation of cognition. First wave theories aim "to model teachers' and students' individual knowledge and beliefs by positing internal cognitive structures and processes that account for their observed activity" (Cobb, 2007, p. 12). They offer robust conceptions of interiorisation and contend that mentalist processes to do with thinking are shaped by social conditions. Second wave theorists offer sophisticated and persuasive criticisms of the central processor model of mind, emphasising affect, context, and culture more than their first wave counterparts. Cognition in this category is typically "situated with respect to...participation in particular social and cultural practices" (p. 12). Such theories tend to problematise conditions of thought as 'holding good' for individuals, irrespective of history, interests and circumstances.

As a first wave theory, the cognitive psychology tradition describes cognition as mental activity to do with interactions and reflections upon the environment. The tradition aimed to show that cognition can be structured and that it cannot but be inward-directed. Cognition is equated to intrapsychic activity in response to factors in the environment. In the internal informationprocessing model, for example, it is Descartes' individual, and more specifically, the individual's developing internal representation within the mind (Goldin \& Shteingold, 2001) that becomes the central unit of analysis. Drawing on humanist sensibilities about the individual, constructivists' accounts of cognition necessarily rely on the autonomous learner, understood as the stable, core, knowing agent. The influences of Piaget and the post-Piagetian work of von Glasersfeld are well known (see Steffe, von Glasersfeld, Richards and Cobb, 1983). Within these accounts, the mind is privileged, while circumstances and conditions are cut down to size.

Second wave theories, for example, sociocultural perspectives that draw their inspiration from Vygotsky's (e.g., 1978) work, developed largely independently of western cognitive psychology. In opposition to the cognitive psychology's privileging of interior mental processes, sociocultural theory (see Davydov \& Radzikhovskii, 1985; Engeström, 1987; Leont'ev, 1978), marks up social contexts and experiences. In seeking to reverse the terms within the individual/social binary, sociocultural theory gives priority to shared consciousness, or intersubjectivity, arguing that conceptual ideas proceed from the intersubjective to the intrasubjective. Cognition involves 
active construction by the individual and evolves through social interaction. In this formulation, since social practice is a mechanism that informs thinking, the way in which mathematical truths are constituted interactively by the classroom community is integral to analyses of classroom life.

In the route from first wave scholarship to contemporary work in the discipline, the epistemological privilege has moved from a philosophy of the subject centred around the idea of a self-sufficient, self-centred subject (and that celebrates the cogito, the reasoned self, that doubles as the objective agent of cognition and of history) to one in which the subject is animated by negotiations of self with social structures and culture. Contemporary interests and issues within mathematics education now concern the complex transactions that take place between the subject-in-process and the structures and processes of mathematics education but what is curious is that traces of the Cartesian model continue to survive. As a consequence, the "flows of what is and is not subjectivity" (Thrift, 2008, p. viii) are never fully captured. We propose a theoretical pathway that accounts for those flows, suturing the social, discursive, temporal, spatial and the psychic in an understanding of experience. We do this by drawing on Spinoza's theoretical tools to explain cognition in mathematics classrooms in relation to the dynamics of the spaces people share and within which they participate.

\section{SPINOZA}

Spinoza's theory provides an exceptionally sharp instrument for animating contemporary thinking about subjectivity in the analysis of teaching and learning in mathematics classrooms. His work offers a description of the 'bare bones' of actual occasions and events; of what is present in experience. Confronting at its core, Descartes' conception of the relationship between body and mind, reason and emotion, and so forth, Spinoza offers a view of how thinking crystallises, in a way that engages affect as constitutive of, rather than subordinated to, the process of cognition. He substitutes the Cartesian understanding of being as origin of presenceas requiring no guarantee outside the unitary and fixed concept of the subject - with a view that has resonance with the argument that "life pretty well always exceeds its own terms and conditions: it is not always captured by the small print of the social contract" (Thrift, 2008, p. 21). Thus, Spinoza's (2000) view of the social world dissolves the common ground of the meanings we make of thinking and being, mapping out new coordinates of the multiple worlds of self in relation to others. These are new explorations that are at once unsettling and enriching. In particular, his Ethics inaugurates a different problematic of being, adding an affective spin to enactivism's (see Davis \& Simmt, 2003; Maturana \& Varela, 1987; Towers \& Davis, 2002). assertion that thinking and being are never inseparable It is by ascribing the active outcome of the cognitive/physical encounters to emotion or affect (affectus), that Spinoza reworks the politics of ontology.

There is no longer a subject, but only individuating affective states of an anonymous force. The plane is concerned only with movements and rests, with dynamic affective charges: the plane will be perceived with whatever it makes us perceive, and then only bit by bit. Our ways of thinking or writing change according to the plane upon which we find ourselves. (Spinoza, cited in Alliez, 2004, p. 27)

Rather than setting up a dualism, actualised in many first and second wave theories, in which affect is in opposition to cognition, Spinoza defines affect as both body and thought. He draws 
attention to the landscape of the multiple worlds that different people inhabit. For him, affect detaches 'the emotions' from 'the realm of responses and situations and attaches them instead to action and encounters as the affections of substance or of its attributes and as greater or lesser forces of exisiting" (Thrift, 2008, p. 178). Thus, Spinoza challenges the assumption that emotions come from within individuals and extend outwards. Rather, for him, they are a crucial aspect of the body's anticipation of the moment, "akin to a natural force of emergence" (Thrift, p. 182). In Spinoza's (2000) words:

By EMOTION (affectus) I understand the modifications of the body by which the power of action of the body is increased or diminished, aided or restrained, and at the same time the idea of these modifications. (Ethics 111, def. 3)

In challenging the idea that affective states are an inner interior experience, often able to be captured as an external observable behaviour, Spinoza moves thinking and being towards an understanding of a collective enterprise, always already operative upon us and within us. Thinking is not created solely from rational decision making and negotiations of self with social structures. Thinking, for Spinoza, is a form of affective 'engineering' that gradually pulls itself into existence, while producing new forms of power on its pathway. It follows, then, that affect is a form of thinking that is often obscure and nonreflective. "Affect structures encounters as a series of modifications arising from the relations between ideas which may be more or less adequate and more or less empowering" (Thrift, p. 179). Emotions are an effect, rather than a representation of the experience of interacting with social groups, cultures and institutions, in specific spaces and in specific times. They are heavily influenced by cultural experiences that serve to regulate how we feel, as well as the initiation and display of specific emotions.

The relational nature of Spinoza's ontology allows him to suggest that our capacity to think and act is produced by mutually reinforcing collaborative activities and practices. As Deleuze (cited in Ruddick, 2010) puts it:

We cannot come to know ourselves, and we cannot come to know external bodies except through the affections that external bodies produce on our own...[This] excludes all apprehension of the thing 'thinking by itself'...all possibility of cogito. I never know anything except the commingling of bodies and I do not understand myself except by the action of other bodies upon me and by these comminglings. (p. 28)

Coming to know mathematics pedagogy means coming to know the affections produced. It is in this sense that mathematics pedagogy is an important affective technology through which teachers become primed to act. That the subliminal as well as the outwardly planned practices of pedagogy can have import draws us to a new understanding of being and knowing and its embeddedness in spatial, temporal and political processes. Instead of a model of cognition located in practices, linked to the autonomous subject, we might understand affect as the cornerstone to understanding the politics of ontology.

\section{EXAMPLE ONE}

Developing a mathematical community

The first site is a low-stream (underachieving) Year 9 class in a New Zealand mathematics classroom within a co-educational school that caters for around 800 students from Year 9 (13 
years of age) to Year 13 (17 years of age). One of us entered the classroom in 2009 as a researcher in a project, which involved videotaping ten consecutive lessons on decimals. We draw on that data as well as data taken from interviews with individual students and the teacher, separately, immediately after each lesson. This dataset provided a database sufficiently complex to support an analysis of the affect/cognition relation within pedagogical practice.

Key to abbreviations in analysis:

I Interview at end of project

I, L1 Interview following lesson 1

Mr Polson is Head of Mathematics at this school. It will be useful to know that he is identified by the local educational community as an effective mathematics teacher. The students in his class are generally from disadvantaged socio-economic backgrounds and have diverse ethnic affiliations. Spinoza's work enables us to explore the way in which he maps out a pedagogical imaginary from the diversity that is a feature of his students.

Prevailing mathematics education policies and discourses at his school invoke a commitment to a wider understanding of diversity than was previously expressed through stereotypical images based on group affiliation. The teachers were asked to reconcile the mathematical identities that they make possible for students to construct in the classroom, with their participation in the practices of home communities, local groups and wider communities within society. As a result, the content of what presents in pedagogical experience at the school changed. As Mr Polson noted, the reforms initiated a "changed relationship with students....It's no longer 'do this because I say' type thing” [I]. At the school equitable teaching practices had become a crucially important driver to embrace diversity and to redress social injustices.

Setting up equitable arrangements for his students required different pedagogical strategies founded on an ethic of care. As Mr Polson pointed out: "You kind of take care of the kids in your class" [I, L2]. He demonstrated his caring in his relations with their students by establishing a classroom space that was hospitable. His classroom practice did more than comply with "the politeness norm that dominates most current teacher discourse" (Ball \& Cohen, 1999, p. 27). Rather, it was founded on an ethic of care that worked at developing interrelationships that opened up spaces for students to develop their own mathematical identities, providing them with opportunities to ask why the class is doing certain things and with what effect.

In implementing the intent of his school policies on equity and diversity, Mr Polson mobilised a subjectivity that was already mapped out for him. The policies provided the coordinates of the multiple worlds of self-in-teaching in relation to others, and they did this in ways that were unavoidably political. In that sense, Mr Polson's affective states were being regulated and shaped within mathematics education in a specific way at the time of the research. Such practices operated to normalise and regulate not only his mathematical teaching practice, but also his "embracement of certain emotional styles" (Thrift, p. 176). His emotions, like those of all other teachers, formed a moral matrix through which and with which mathematics pedagogy could be thought.

That kind of intelligence was not always possible for him to name. Spinoza clarifies: "Men are deceived in that they think themselves free, an opinion which consists simply in the fact that they 
are conscious of their actions and ignorant of the causes by which those actions are determined" (Ethics II, p. 35). Mr Polson had come to recognise, respect, and value the mathematics of the diverse cultural groups within his class. In that 'work', an affective-evaluative coupling, associated with the regulation of teaching for diversity, provided a vehicle for him to make his own assessment of the prevailing discourses on mathematics teaching. As Negri (cited in Ruddick, 2010) describes it: "the ontological immediacy...gains normative capability" (p. 27). It was through his affective-evaluative schema, that Mr Polson was able to make a change from traditional practice. In a similar way to the teacher in a study undertaken by Angier and Povey (1999), he worked hard at developing a web of relationships that allowed every student to develop the sense of belonging. As he said:

My hope is always to get a fully functioning class where everybody gets on with each other and, you know that thing about 'each according to his needs and each according to capabilities' type thing? I quite like that idea. You do have to have different expectations with different kids. So to have them to respect each other and to learn something, it's just like the social thing comes before the learning thing. [I, L1]

Mr Polson took pains to ensure that he nurtured every student, irrespective of mathematical proficiency: "Phoebe is a step behind the others and I have to be careful what I ask her because I don't want to embarrass her" [I, L2]. When a new girl joined the class on day 3 of the research he asked her at the end of the lesson to read out the answers to the day's mathematics problems. "I guess she sees that as being part of the class - that she has contributed something... The class has seen her, and they have heard her voice" [I, L3].

The caring and social nurturing that took place in this classroom implied respect. Michelle explained that it's "a two way thing because to get respect you have to respect back, like you have to give them respect before you get respect back." Respectful practice involved listening carefully to students. Michelle made the point:

He actually listens to what we are saying because most teachers don't. They don't really care what we are saying and they think they are always right all of the time and they won't listen to our side of it. Mr Polson takes it on and thinks about it instead of just letting it go.

Careful listening demonstrated a respect and intellectual support for students on the part of the teacher (Hackenberg, 2010). However, lack of consistent student attendance in mathematics class presented a dilemma for him, focused as he was on providing the affective support that might promote cognitive development. As he noted:

I think we had 26 or 27 students today. The other day we were about $15 \ldots$ It makes it tricky. One boy had $50 \%$ attendances a term. Kylie at the back of the room left school two weeks before the end of term one and didn't attend any school then came back at the end of the second term. So they come and go. Another girl Danielle was away a whole week last week and Hemi was also away a whole week...So it's an interesting class because of that. [I, L3]

Uneven daily engagement was also an issue: "The first day of the week they are pretty hyper[active]; after a long weekend particularly. As the week goes on they get much more settled" [I, L3]. The economic and material disadvantage that goes hand in hand with nonattendance and differential lesson engagement operates to structure the overall learning opportunities that were made available to the class. The classroom as a collective enterprise is 
always already operative upon him and within him. Though Mr Polson's affective response can never be fully anticipated, clearly his response will not be random.

\section{Developing mathematical proficiency}

Teachers build their practice on specific beliefs about learning and knowing mathematics. $\mathrm{Mr}$ Polson is confident in the reasoning powers of his students. He said: "Part of it is to do with their confidence in their own knowledge. Part of it is to do with them trusting me as a teacher" [I, L10]. He noted during his final interview at the conclusion of the project: "I like getting the kids writing on the board and getting them interacting" [I]. Like the teachers in Watson's (2002) study, the value he placed on students' thinking and reasoning influenced the way in which the students viewed their relationship with mathematics. Within the supportive community $\mathrm{Mr}$ Polson had established, students were confident in the soundness of their mathematical identities.

All ten students interviewed believed they were good at mathematics. When asked what makes a good mathematics student, they responded variously, "listening and taking everything in and talking at the appropriate times," "being cooperative," "responsible when you are putting your hand up to talk," "trying your hardest one hundred percent," "paying attention and doing everything right," "knowing your times tables," and "doing the work." However, the kind of mathematical identities the students had been encouraged to create tended to be inflated, developed without consideration to higher-level thinking and deep conceptual understanding. In the following excerpt taken from lesson 9, the class has been working out how many tenths there are in 3.2 .

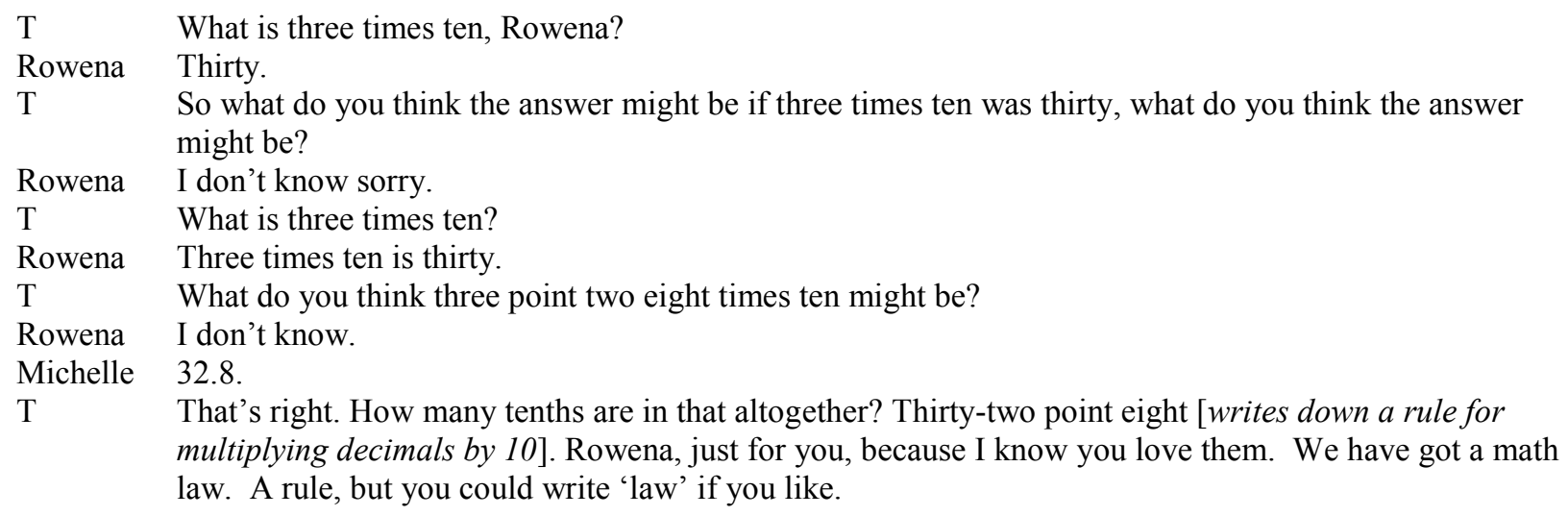

After the lesson Michelle (M) was interviewed about her answer:

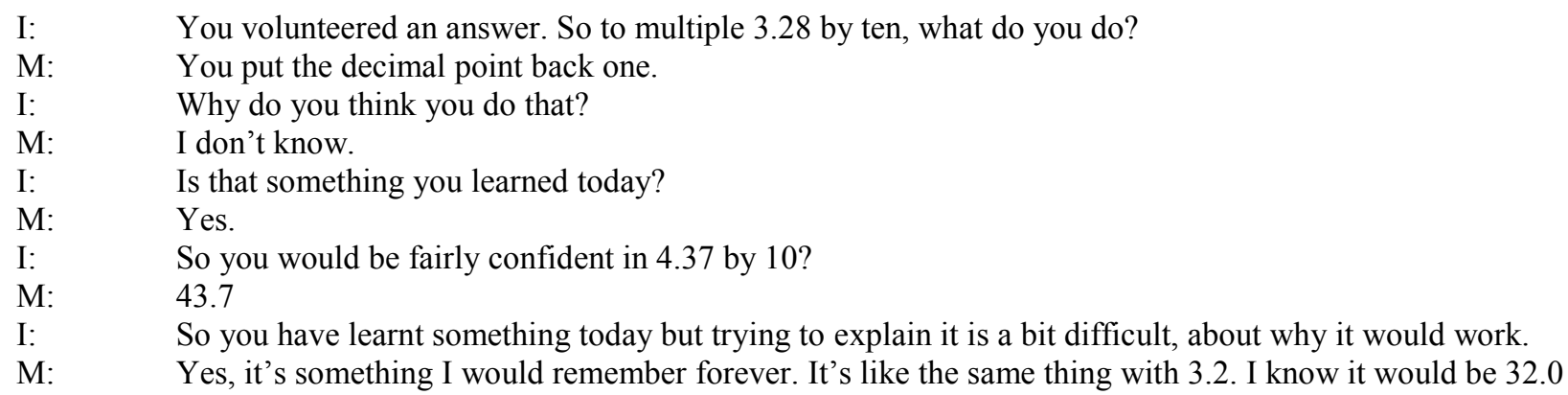

The interviewer moved to inquire about her understanding of decimal ordering. 
I: $\quad 0.021$ and 0.87 . How could you know which is the smallest or largest using Mr Polson's rule?

M: $\quad 0.021$ is higher because it has more digits behind the decimal point so that is how I know. And if they have the same number of digits you put them in the order of numbers.

I: $\quad$ If they have got different digits you look for the one that has the most digits?

M: Yes.

I: $\quad$ Do you understand his rules? Did you understand this or did you just copy this down and not think too much about it?

M: $\quad$ He said we can do our strategies or his strategies.

I: $\quad$ So it is a rule to fall back on if you are not sure?

M: $\quad$ Yes, if you don't know what you are doing.

Thompson (2008) has noted that in many classrooms, students "rarely experience a significant mathematical idea and certainly rarely experience reasoning with ideas" (p. 31). Supporting a large body of writing that emphasises the importance of student engagement with the big ideas of mathematics (e.g., Kazemi \& Franke, 2004; Wood, Williams, \& McNeal, 2006), student experience of mathematical reasoning has become a privileged teaching practice, scripting pedagogical interactions. It is important to note that such pedagogical arrangements herald in a series of affective technologies, allof which operate within the small spaces and times of classroom life. Within the constraints imposed, Mr Polson oscillated between an evaluative grid for pedagogy that honoured student reasoning, with one that celebrated student participation. Given his awareness of the affections produced on his students by the two pedagogical approaches, Mr Polson opted for the use of rules, repetition of tasks, and small procedural steps.

He explained his actions in this way: "You have to make a judgment sometimes when you are going to push it and where you are not... I have always felt that people have got different capabilities and you don't have one size fits all" [I, L10]. Rather than focusing on high-level reasoning with mathematics his primary motivation was in providing support for students to actively engage with mathematics. He monitored their engagement and ensured that they understood the problem and, where necessary, adapted the level of difficulty for them. As he noted: "You make decisions as you go along and you make decisions according to feedback that you are getting from the class. Sometimes you will interpret the right way and sometimes you won't' [I, 12]. In each encounter within the classroom, affect presented differently to his mind and his body. Moreover, in each encounter, he implicitly articulated the Nietzschean realisation that "between two thoughts all kinds of affects play their game; but their motions are too fast, therefore we fail to recognise them" (Nietzsche, 1968, p. 263). Thrift (2008) puts it this way:

In the attribute of body, affect structures encounters so that bodies are disposed for action in a particular way. In the attribute of mind, affect structures encounters as a series of modifications arising from the relations between ideas which may be more or less adequate and more or less empowering. (p. 179)

In an understanding informed by Spinoza's work, particular categories of students, such as 'low ability', or 'disadvantaged' invoke specific affective responses from teachers. Those responses are developed from both practical and theoretical knowledges derived from a wide range of sources. They are constituted through specific cues such as mathematics education documents and discourses. They are also constituted subliminally, through more general archives of classroom events. This is where emotions become "a kind of corporeal thinking" (Thrift, 2008, p. 176) and what it means to teach mathematics is captured through an affective response of student (in)capability and disadvantage. 
It could be claimed that Mr Polson's slowly paced and sequenced examples made it possible for students to access knowledge, that they supported struggling students and that they assisted students to grasp their misconceptions and errors (see Grossman \& McDonald, 2008). Indeed, his tendency to simplify a task into small procedures was received favourably by his students. John said: "It's easy because he does it step by step." Michelle, who was absent from many classes, pointed out, "I am able to keep up - he doesn't move that fast." And as Kelly volunteered: "the way he tells us the questions - he gives them in an easier form, an easier way to put it so we can work it out easier." The model of pedagogy enacted by Mr Polson is already inscribed in specific discourses of pedagogical practice. Importantly, the model is also constantly refigured by him in each new reenactment of pedagogical practice. This is a refiguration that is not reducible to the psychological model of internalisation. Rather, in Spinoza's understanding, it is a way of folding the outside inside oneself, through the real or imagined participation of others. Mr Polson summed it up:

I think that I am probably more aware of the good things that are happening in the classroom because sometimes as a teacher I have always been a bit on edge and there has always been a sense of urgency to things that I have done. Like a herd of cattle or something you have to move them this way, or a herd of sheep maybe, and you have got to be nipping around the edges of them making sure that they are all getting together. I think that somewhere along the way I have decided that that urgency has perhaps not always been helpful and that things can get along without having that sense of urgency [I]

Mr Polson's thinking and being in this classroom might be read as an emergent outcome of strategic joint action, linked to both loss and to anticipation. In this action cognition/affect monitors and interprets others' meanings and the temporal and spatial conditions that are associated with those meanings, in a manner that is suggestive of the way in which telepathy is said to 'read the mind'. Its function is archival, operating through codes, folds and capacities. Given that the work that cognition/affect does involves such high-level social awareness and manipulation of meaning, time and space, it is a truly remarkable accomplishment. It explains why Mr Polson looks "simultaneously to the common advantage of all" and seeks for himself nothing that he "would not desire for the rest of human beings" (Spinoza, 2000, Ethics IV, p. 18). For Spinoza, this is "not a moral imperative...but an immanent reality" (Ruddick, 2010, p. 25). It explains the modality of hope through which Mr Polson responds to diversity and low proficiency issues and through which he works through the ethical dilemmas that confront him in the classroom.

\section{EXAMPLE TWO:}

One of us teaches a group of first year undergraduates, mainly in their early twenties, training to be teachers in secondary schools. The course is designed to broaden their perceptions of mathematics, fresh as they often are from an exam oriented school curriculum. Two or three of the three-hour sessions are devoted to the apprehension of planetary movements and geometric entities (see also Brown, 2011). A sequence of exercises entailing bodily movement relate to the relative configurations of earth moon and sun and how these configurations might be seen from alternative perspectives (from deep space, from the surface of the earth, etc.). The purpose of the sessions is to enable students to share their attempts to apprehend the configurations at different times of day or year. 
Ashley, Mandy and Danielle seek to share their perceptions of how the moon moves in relation to the earth. They appear to be vividly sharing an apprehension but they experience difficulty in communicating this apprehension in words. A flurry of successive attempts interrupts each other:

A: $\quad$ Because we are on an angle of let's say this way I am looking at it... as we come round if we keep on that angle we only ever see my face, you never see the back of my head.

M: It doesn't matter whereabouts.

A: Yeah you split...

D: Ashley's focus stays on that ball so her body might be turning but she is still looking...

A. So you only ever see...

D: So, if someone is stood on there, they would only ever see my face, not the back of my head, otherwise I'd be going...

M: We must be right because we are all on the same wavelength. We all agree.

A: $\quad$ If I could spin myself like this ...

M: The moon's just on an angle. That's what it is. Spin round double ... see it's worked... best logic I've thought of.

The mathematical object in question is a circle (or ellipse). Yet the perspectives assumed of this circle obscure its appearance as a clear cut geometric entity. The task was centred on being able to apprehend an orbit from various given perspectives, such that the students were challenged to situate themselves within and experience mathematically conceived space. The question of moving around this ellipse whilst maintaining the correct orientation further complicates the sharing of perceptions in words. The keenly felt perception of being of the "same wavelength", however, somehow reduced the need for a clear set of words. Indeed, the desire for a correct set of words seemed destined to fail as the power of shared movement became far more communicative.
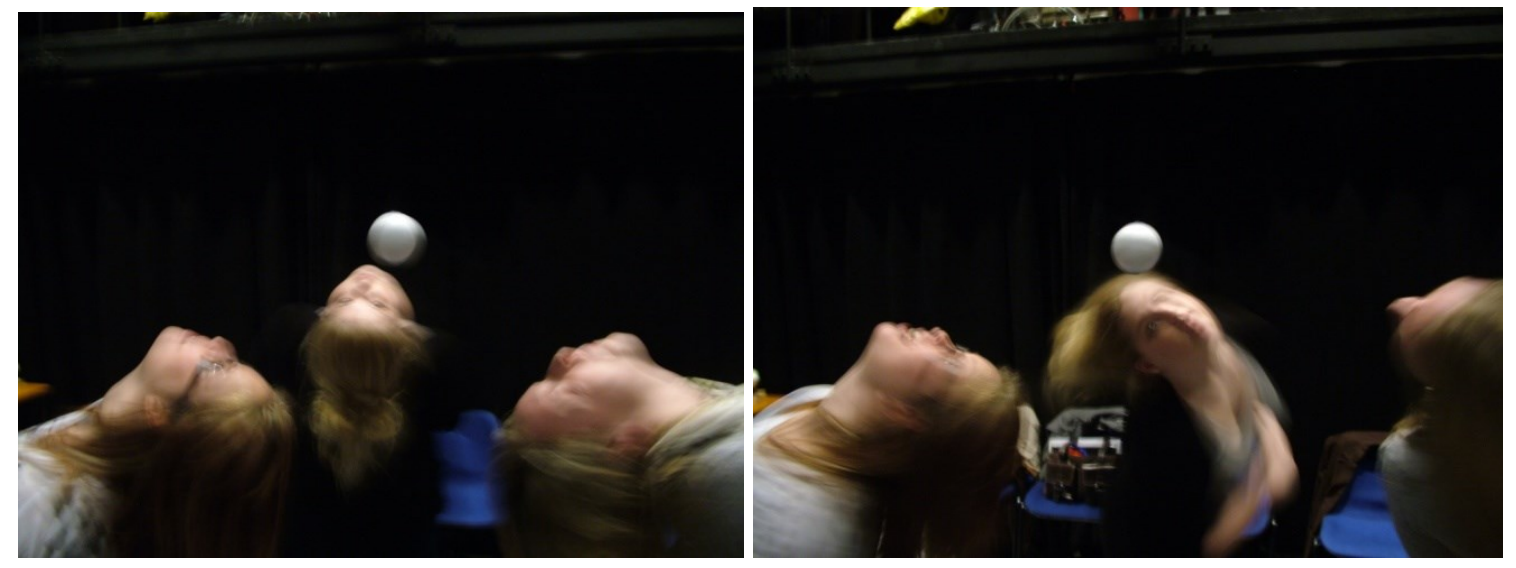

Finally, they enacted the orbit of the moon through bodily movements that seemed remarkably coordinated, with all three students moving in the same trajectory around a suspended sphere (the earth), where they each maintained a constant orientation to the earth throughout.

How might we understand the quest for knowledge here in Spinozan terms? "Spinoza's 'good man' will in fact be good in the normal sense. He will naturally try to bring it about that others are free and wise" (Urmson \& Ree, 1991, p. 305). This suggests a pedagogical attitude in which the teacher is more concerned with hearing his students' constructions than with ensuring that the 
"correct" message is delivered. "He knows that the only object worth pursuing, knowledge, is better attained in companionship than alone, but he also knows that everyone has their own conatus, and no matter how mistaken they may be about how best to 'persevere in their own being', they have the same right as the wise so to persevere" (ibid). Whilst the existence of the ellipse might be secured in the terms of "scientific knowledge" there is some risk that this would have crushed the powerful insights that were being achieved through shared movement, and the very attempts to share. The science police would be depleting the experience of science. Spinoza's Ethics alerts us to the fact that:

The expansion of our capacity to act is at once relational, produced by mutually reinforcing collaborations and the outcome of a complex interplay of affect and reason. It is through this interplay that we move from a passive experience of joy to an active understanding of the nature of the associations that empower. (Ruddick, 2010, p. 26).

Badiou (2006, p. 130) identifies his own conception of truth in the work of Spinoza. "Truth is the proof of itself. There is no external guarantee". Any configuration of the ellipse in "scientific knowledge" validates within that culturally-specific domain of knowledge but might deplete the experience of its truth for these students, sensed as a moving circular orbit. In relation to Badiou's (2009) conception of truth, cultural or scientific knowledge never quite keeps up:

But the truth at issue, by the thrust of the real, produces a deficit in the symbolic whereby the subject, as courage, turns the radical absence of any security into its force, In this process, the subject truly loses its name, besides it is also one of Spinoza's theorems that security desubjectivises... Security is the sign of a subjective impotence. (p. 160)

In Badiou's terms knowledge will always need to be renewed (Brown, 2010). The three students are sharing "fidelity" to an experience of truth that defies final capture in a symbolic configuration, but it also defies final capture of themselves in finished form. Their subjectivity is defined with respect to a lived experience, a moving state of affairs, not a fixed relation of object (an elliptical orbit) to subject (held by a name). Their thinking changes according to the plane upon which they find themselves. The affectivity of the space teaches the students to recognise their position or orientation in time and space through sensual clues, for example, shadows, direction of moon, darkness, temperature, foliage, reciprocities of sharing space with others. Their emergent spatial and temporal awareness marked by these qualitative features occurs as part of a layering of complex systems of relationships and spaces within constantly changing circumstances and conditions. The space that the students occupy is beyond the reach of quantifiable scientific knowledge, a knowledge that provides security and a depletion of life. The regulation that has come to prevail in many education administrations has forced aspects of mathematics in to very narrow agenda governed by performance in tests. This is not always a good background for those wanting to teach, if teaching is to be any more than routine working through successive exercises.

There is an ethical choice in favour of the richness of the possible, an ethics and politics of the virtual that decorporealizes and deterritorializes contingency, linear causality and the pressure of circumstances and significations which beseige us. It is a choice for processuality, irreversibility and resingularization. On a small scale, this redeployment can turn itself into the mode of entrapment... But it can also make use of other procedures that are more collective, more social, more political. (Guattari, 1992, p. 94) 


\section{CONCLUSION}

Mathematics education is a complex and multilayered practice (Anthony \& Walshaw, 2007). In many contemporary approaches to teaching and learning, the argument that thinking evolves through social interaction has become a cornerstone to the constitution of teaching and learning. However, foregrounding thinking as social is typically proposed at the expense of affect with the result that consideration of the work that teachers and students do in the classroom is given to only one register in which thinking takes place. We have found Spinoza's work useful to explore the multiple registers on which classroom practice operates. Emphasising affect and incorporating the subliminal, Spinoza's ideas serve as a counterpoint to habitual thinking about cognition, acting to fashion a new imaginary about thinking and being. The strength of his work as opposed to the display of its individual jewels is the way it allows us to uncover new terrains of collectivity. Using his work to develop new meanings on cognition requires understanding the knowledges and technologies that operate within collectivities on thinking and actions from encounters and spaces. Such understandings are informed by both practical and theoretical knowleges concerning what it means to teach and learn, and what it means to advantage all. Such insights contribute to our overall understanding of mathematics teaching and learning.

The teacher in the first example developed an overall goal structure that prioritised affective support. Given the discourses on students' diversity that predominated at the school, foremost in his mind was his care of his diverse and low proficient students. Those discourses regulated and shaped his affective states, operating to normalise his mathematical teaching practice, and also to provide a moral matrix through which and with which he thought about mathematics pedagogy. He resolved the ontological divide that presented, in relation to enhancing proficiency by using the resources of a caring community to develop his students' sense of self as mathematical learners. Precisely because he had developed an acute sensitively to his students' affective states, when confronted with the realities of poor student attendance and attention, his instructional practice became oriented towards providing his students with the means to participate in a microcosm of mathematical practice.

In the second example, scientific knowledge was held at a distance to enable the survival of an experience of sharing being played out in bodily actions. Neither the ellipse's objectivity nor the students' subjectivity were in finished states. The account of learning was predicated on a joyous experience through time kept going by the very failure of language to sum things up. Knowledge of affective states, the "nonhuman becomings" (Deleuze \& Guattari, 1994, p. 169) of students, in particular (where affect is conceived as a form of intelligence about the world), allowed the teacher to embrace the discomfort of 'unfinished' knowledge and subjectivity. There is discomfort because it takes us into the unknown. But the unknown is the place where discoveries big and small can be made. As Ruddick (2010) argues, "we must remain open to interrogating the bases of our fears of (or indifferences to) alterity, open to discomfort that is the 'dark precursor' to a new...imaginary" (p. 24). Such openness will allow us to re-shape the contemporary imaginary.

The radical potential of Spinoza's work for mathematics education, in general, and for mathematics teaching and learning, in particular, can be linked to its sustained emphasis on affect as a constitutive rather than derivative quality in life. Pedagogical realities become embedded in spatial, temporal and political processes in which affect becomes a key element. Crucially, knowledge of affective states offers a way of understanding what mathematics 
education might do to effect change, and what it might do to produce tangible results. What is animated is an affective politics that is deeply ingrained within the process of thinking, ethically grounded in collectivity, where collectivity functions "as a kind of aggregate," rather than "in terms of a methodological individualism" (Ruddick, 2010, p. 25). Given the realities that are present within everyday classrooms, such an interrogation is more urgent today than ever before.

\section{ACKNOWLEDGEMENT}

We are grateful to a number of people for their participation in this paper, including Ashley Davies, Mandy Jacques and Danielle Bird.

We are also grateful to the Teaching and Learning Research Initiative for funding the project reported on in example one.

\section{REFERENCES}

Alliez, E. (2004). The signature of the world: What is Deleuze and Guattari's philosophy? London: Continuum.

Angier, C., \& Povey, H. (1999). One teacher and a class of school students: Their perception of the culture of their mathematics classroom and its construction. Educational Review, 51, 147-160.

Anthony, G., \& Walshaw, M. (2007). Effective pedagogy in Mathematics/Pāngarau: Best Evidence Synthesis Iteration [BES]. Wellington: Learning Media.

Badiou, A. (2006). Infinite thought. London: Continuum.

Badiou, A. (2009). Theory of the subject. London: Continuum.

Ball, D. L., \& Cohen, D.K. (1999). Developing practice, developing practitioners: toward a practice-based theory of professional education. In L. D. H. G. Sykes (Ed.), Teaching as the learning profession: Handbook of policy and practice (pp. 3-32). San Francisco, CA: Jossey-Bass.

Bibby, T. (2010). Classrooms and their discontents: Education and psychoanalysis. London: Routledge.

Brown, L., \& Reid, D. (2004). Emotional orientations and somatic markers: Implications for mathematics education. In M.J. H_ines \& A. B. Fuglestad (Eds.), Proceedings of the 28th conference of the International Group for the Psychology of Mathematics Education (Vol 1, pp 123-126). Bergen: PME.

Brown, T. (2008). Lacan, subjectivity and the task of mathematics education research, Educational Studies in Mathematics, 68, 227-245.

Brown, T. (2010). Truth and the renewal of knowledge: The case of mathematics education. Educational Studies in Mathematics. 75(3), 329-343.

Brown, T. (2011). Mathematics education and subjectivity: Cultures and cultural renewal. Dordrecht: Springer.

Cobb, P. (2007). Putting philosophy to work: Coping with multiple theoretical perspectices. In F. K. Lester (Ed.), Second handbook of research on mathematics teaching and learning (pp. 3-38). Charlotte, NC: Information Age/NCTM.

Davis, B. \& Simmt, E. (2003). Understanding learning systems: Mathematics education and complexity science. Journal for Research in Mathematics Education, 34(2), 137-167. 
Davydov, V. V., \& Radzikhovskii, L. A. (1985). Vygotsky's theory and the activity-oriented approach in psychology. In J. V. Wertsch (Ed.), Culture, communication and cognition: Vygotskian perspectives (pp. 35-65). New York: Cambridge University Press.

De Corte, E., Greer, B., \& Verschaffel, L. (1996). Mathematics learning and teaching. In D. Berliner \& R. Calfee (Eds.), Handbook of educational psychology (pp. 491-549). New York: Macmillan.

Deleuze, G. (1988). Spinoza: Practical philosophy (Trans: R. Hurley). San Francisco: City Lights Books. (First published in French in 1981).

Deleuze. G. (1990). Expressionism in philosophy: Spinoza (Trans: M. Joughin). New York: Zone Books. (First published in French in 1968).Deleuze, G., \& Guattari, F. (1994). What is philosophy? London: Verso.

Drodge, E.N., \& Reid, D.A. (2000). Embodied cognition and the mathematical emotional orientation. Mathematical Thinking and Learning, 2, 249-267.

Duffy, S. (2006). The logic of expression: Quality, quantity, and intensity in Spinoza. Aldershot and Burlington: Ashgate.

Engeström, Y. (1987) Learning by expanding: an activity-theoretical approach to developmental research, Helsinki, Finland, Orienta-Konsultit Oy.

Evans, J. (2000). Adults' mathematical thinking and emotions: A study of numerate practices. London: Routledge Falmer.

Goldin, G.A. (2000). Affective pathways and representations in mathematical problem solving. Mathematical Thinking and Learning, 7, 209-219.

Goldin, G., \& Shteingold, N. (2001). Systems of representations and the development of mathematical concepts. In A. A. Cuoco \& F. R. Curcio (Eds.), The roles of representation in school mathematics: 2001 Yearbook (pp. 1-23). Reston, VA: NCTM.

Grossman, P., \& McDonald, M. (2008). Back to the future: Directions for research in teaching and teacher education. American Educational Research Journal, 45 (1), 184-205.

Hackenberg, A. (2010). Mathematical Caring Relations in Action. Journal for Research in Mathematics Education, 41(3), 236-273.

Hannula, M. (2002). Attitude towards mathematics: Emotions, expectations and values. Educational Studies in Mathematics, 49(1), 25-46.

Kazemi, E., \& Franke, M. (2004). Teacher learning in mathematics: Using student work to promote collective inquiry. Journal of Mathematics Teacher Education, 7(3), 203-235.

Lave, J. (1988). Cognition in practice: Mind, mathematics and culture in everyday life. Cambridge: Cambridge University Press.

Leont'ev, A. (1978). Activity, consciousness, and personality. Englewood Cliffs, NJ, PrenticeHall.

Ma, X. (1999). A meta-analysis of the relationship between anxiety toward mathematics and achievement on mathematics. Journal for Research in Mathematics Education, 30(5), 520-540.

Martinez, J.G. R., \& Martinez, N.C. (2003). Raising middle school math standards without raising anxiety. Middle School Journal, 34(4), 27.

Maturana, H. and Varela, F. (1987). The tree of knowledge: The biological roots of human understanding. Boston, MA, Shambhala.

McLeod, D.B. (1992). Research on affect in mathematics education: A reconceptualization. In D. Grouws (Ed.), Handbook of research on mathematics teaching and learning (pp. 575- 
596). New York: Macmillan.

Nietzsche, F. (1968). The will to power. New York: Vintage.

Ruddick, S. (2010). The politics of affect: Spinoza in the work of Negri and Deleuze. Theory, Culture \& Society, 27(4), 21-45.

Schlöglmann, W. (2002). Affect and mathematics learning. In AD. Cockbum \& E. Nardi (Eds.), Proceedings of the 26th conference of the international group for the Psychology of Mathematics Education (Vol. 4, pp. 185-192). Norwich, UK: University of East Anglia.

Spinoza, B. (2000). Spinoza: Ethics. (Trans: G. H. R. Parkinson). New York: Oxford University Press.

Steffe, L., von Glasersfeld, E., Richards, J. and Cobb, P. (1983) Children's counting types: Philosophy, theory, and application, New York, NY: Praeger.

Thompson, P. W. (2008). Conceptual analysis of mathematical ideas: Some spadework at the foundation of mathematics education. In O. Figueras, J. Cortina, S. Alatorre, T. Rojano, \& A. Sepúlveda (Eds.), Proceedings of the Joint meeting of PME 32 and PME-NA XXX (Vol.1, pp. 31-49). Morelia, Mexico.

Thrift, N. (2008). Non-representational theory: Space, politics, affect. London: Routledge.

Towers. J., \& Davis, B. (2002). Structuring occasions. Educational Studies in Mathematics 49(3), 313-340.

Urmson, J., \& Ree, J. (Eds.). (1991) The concise encylopedia of western philosophy and philosophers. London: Unwin Hyman.

Vygotsky, L. (1978). Mind in society: The development of higher psychological processes. Cambridge, MA: Harvard University Press.

Walshaw, M. (2010). A Foucauldian gaze on gender research: What do you do when confronted with the tunnel at the end of the light?" In A. J. Bishop (Ed.), Mathematics Education (Vol. 3, pp. 108-128). London: Routledge.

Watson, A. (2002). Instances of mathematical thinking among low attaining students in an ordinary secondary classroom. Journal of Mathematical Behavior, 20(4), 461-475.

Williams, C. (2007). Thinking the political in the wake of Spinoza: Power, affect and imagination in the Ethics. Contemporary Political Theory, 6, 349-369.

Wood, T., Williams, G., \& McNeal, B. (2006). Children's mathematical thinking in different classroom cultures. Journal for Research in Mathematics Education, 37, 222-252. 